\title{
Evli Çiftlerde Bağlanma Stillerinin ve Ontolojik İyi Oluşun Cinsel Doyum Üzerine Etkisi
}

\author{
DOI: 10.26466/opus.851659 \\ * \\ H. Kübra Yılmaztürk Yıldırım* \\ * Dr. Öğr. Üyesi, Samsun Üniversitesi, İISF Psikoloji Bölümü, Samsun/Türkiye \\ E-Posta: hkubra.yildirim@samsun.edu.tr \\ ORCID: $\underline{0000-0002-3519-4867}$
}

\section{Öz}

$B u$ araştırmada evli çiftlerin bağlanma stilleri ile ontolojik iyi oluş düzeylerinin cinsel doyum üzerine etkisi araştırılmıştır. Çalışmada, bă̆lanma stillerinin cinsel doyum üzerindeki etkisi araştırılırken, aynı zamanda bireyin yaşam projesinin yani ontolojik iyi oluşunun (OiO), geçmiş, şimdi ve gelecek tasavvurlarının cinsel doyumu üzerindeki etkisinin ortaya çıkarılması amaçlanmaktadır. Sonuç itibarıyla çiftlerin bağlanma stillerinin cinsel doyum üzerindeki etkisi ve ardindan sürece yaşam projesi ölçeği (YPÖ-OWBS) katıldıktan sonra, cinsel doyumda açıklanan varyansa istatistiksel olarak anlamlı katkısı olup olmadığı incelenmiştir. Araştırmanın evrenini, 2017-2018 yıl içerisinde çeşitli illerde (İstanbul, Ankara, Samsun, Bursa, İzmir, Eskişehir, Elazı̆̆, Ordu, Düzce, Kocaeli, Sakarya) bulunanan evli çiftler oluşturmaktadır. Araştırmanın örneklemi belirlenen illerde yaşayan ve random olarak seçilen evli çiftlere, ölçeklerin kapalı zarf içerisinde verilerek, gönüllülük esasına dayalı şekilde uygulanmasıyla oluşturulmuştur. Örneklem 23-63 yaş arası 215 çiftten (215 kadın, 215 erkek N=430) oluşmaktadır. Araştırmada Kişisel Bilgi Formu, Yakın Ilişskilerde Yaşantılar Envanteri II (Yiye II), Golombok-Rust Cinsel Doyum Ölçeği (kadınlerkek) ve Yaşam Projesi Ölçeği (YPÖ) kullanılmıştır. Bulgular değerlendirilirken, istatistiksel analizler için SPSS 25.0 programı kullanılmıştır. Kurulan modelin sonucuna göre; evli çiftlerin bağlanma stillerinin üzerine, ontolojik iyi oluş düzeylerinin cinsel doyumda artışa etkisi olduğu görülmüştür.

Anahtar Kelimeler: Yetişkin bağlanma stilleri, ontolojik iyi oluş, yaşam projesi, cinsel doyum, öyküsel perspektif. 


\title{
In Married Couples Attachment Styles' and Ontological Well-being's Effect on Sexual Satisfaction
}

\begin{abstract}
In this study, married couples' attachment styles' and ontological wellbeing's effect on sexual satisfaction levels is investigated. In the study, while attachment styles' effect on sexual satisfaction is investigated, at the same time, it is aimed to reveal the effect of individual's life project i.e. ontological well-being and his concept of past, present and future on sexual satisfaction. In consequence, couples' attachment styles' effect on sexual satisfaction and then after the ontological wellbeing questionnaire has entered into the process, whether it has a statistically meaningful contribution to the variance on sexual satisfaction is investigated. The universe of the study consists of married couples in different provinces in 2017-2020. The sample of the study was created by applying the scales in a sealed envelope to married couples who were randomly selected and accepted to participate in the study. The sample consists of 215 couples (215 females, 215 males $N=430$ ) between the ages of 21-63. In the study, Personal Information Form, Experiences in Close Relationships II Questionnaire (ECRR), Golombok Rust Inventory of Sexual Satisfaction (female/male) and Ontological Wellbeing Scale (OWBS) are used. According to the result of the established model; On the attachment styles of married couples, it was observed that ontological well-being levels had an effect on the increase in sexual satisfaction.
\end{abstract}

Keywords: Adult attachment style, ontological well-being, life project, sexual satisfaction, narrative perspective. 


\section{Giriş}

İnsanın ilişki isteği, fiziksel boyutun ötesinde anlamlar barındırmaktadır. Bu istek duygusal boyutta ise bağlanma olarak isimlendirilir (Bilgin, 2001, s.205). Bir çocuğun ayrılma ve kaybetme ile karşılaştığı yer ilk bakım verenin şahsında meydana gelir. Bu ayrılığa ve kaybetme durumuna verilen tepkinin anlamı, onu bu figüre bağlayan ilişkinin anlamında gizlidir (Bowlby, 2012, s.233). Bowlby, bağlanmanın kendine özgü bir ilerlemesinin olduğu, yalnızca üreme ve beslenme sistemlerinden hareket alan bir yapı olmadığı görüşünü ortaya atmıştır. Bağlanma, evrimsel olarak bebeğin büyüyüp gelişmesine engel olan durumlardan koruyacak bir bağlanma figürü ile ilişki kurma davranışı olarak tanımlar (Bretherton,1992).

Yenidoğan ve ona bakım veren arasındaki bağ sadece sevgi bağ1 değildir, bununla birlikte bilişsel, duyuşsal, sosyal ve daha başka birçok alanda bebeğin gelişimine katkıda bulunacak ve onu hayatı boyunca yakın ilişkilerinde de takip edecek bir yapı olduğu söylenebilir (Sümer, 2002). Bahsi geçen ilişkinin bütününde, bakım veren ve ebeveyn arasında tekrarlandıkça bir örüntü haline gelmektedir. Tekrarlayan güvenli deneyimlerin neticesinde çocuk kendi oluşuna dair kabulü ve birikimleri ile birlikte bağlandığı kişilerle bağlanma biçimlerini ve bağlanma tecrübelerini de kapsayan bir 'içsel çalışan model' geliştirir. Kişiye özgü ve kişinin hem kendilik hem de öteki tasarımını içine alan bu modeller, yaşamın ilk dönemlerinde gelişmeye başlayarak sonrasında da daimi olarak gelişmeye ve değişmeye devam eder (Diehl, Elnick, Bourbeau ve Labouvie-Vief, 1998).

Bağlanma ve cinsellik kavramlarının her ne kadar kendine ait aktive alanı, yöneldikleri nesnenin farklılı̆̆ 1 ve gelişim süreçleri farklı evrelerde meydana gelse de bu iki kavram birbirinden bağımsız değillerdir (Bowlby, 1969/1982). Shaver ve Miculincer'a göre yetişkin bağlanma sistemleri arasındaki bireysel farklılıklar da erken yaşlardan itibaren sistemli olarak maruz kalınan ve içsel olarak biriktirilen bu süreçten etkilenerek gelişmektedir. Diğer ilişkilere nispeten bağlanma ilişkilerinin ayırt edici yanı, özellikle geçmişe gönderme yapar biçimde bebeğin annesinden ayrıldığında hissettiğine benzer olarak, bağlanılan kişinin diğer kişide güven ve ait olma duygusu meydana getirmesi, yokluğunda ise yalnızlık 
ve tedirginlik yaşatmasıdır (Şahin ve Yaka, 2010). Araştırmalar ve çalışmalar sonucu gelinen nokta itibarıyla denilebilir ki; güvenli bağlanma ilişkilerin daha sorunsuz yapılandırıldığını ifade ederken, güvensiz bağlanma bağlanmaya ilişkin kaygı ve kaçınma olmak üzere birbirinden bağımsız iki boyutda farklılaşma göstermiştir (Sümer, 2006b; Sümer 2009).

Güvenli bireyler romantik ilişkilerinde de genel anlamda daha mutlu, kendine güvenli ve partnerin hatalarına karşı daha anlayışlı ve destekleyici bir tutum sergilemektedirler. Araştırmalar aynı zamanda kaygılı bağlanan bireylerin, erken dönem yaşantılarına ve aile içi ilişkilere dair, "hem yakın ve ihtiyaçları karşılayıcı hem de uzak ve kestirilemez tarafları olan" tanımlamasının yapıldığını göstermektedir. Bu yetişkinlerin, partnerlerini fazla yücelttikleri, idealize ettikleri, ulaşılması güç bir yere koydukları, terk edilme endişesi duydukları, cinsel çekim takıntılı oldukları, kıskanç ve duygusal açıdan inişli ve çıkışlı bir tavır sergiledikleri gözlenmiştir. Kaçınganlar ise ilişkiden ve ilişkideki yakınlıktan kaçınmakta, ilişkiye dair beklentilerini düşük tutmakta bununla birlikte talepleri karşılamaktansa, ilişkiye uzak durmakta ve partnerlerine soğuk davranmaktadırlar (Hazan ve Shaver, 1987).

İlgi alanyazın incelendiğinde çalışmanın değişkenlerinden olan ontolojik iyi oluş (İO) kavramının temelleri, iyi oluş temelinde Aristoteles'e kadar dayandığı gözlenmektedir. Aristoteles, insan davranışının hem motivasyonunda hem de ulaşılan en üst noktasında iyi oluş (hedonizm) olduğunu belirtmiştir. Felsefi ve psikolojik alanyazın, hayatın bütün olarak algılanabilmesinin, ancak bütün zaman perspektifinden kavramsallaştırılmasıyla mümkün olduğunu belirtmektedir. Tam da bu noktadan hareketle öznel iyi oluş (ÖİO) yaklaşımına gelen en önemli eleştirilerden biri, bu alanyazınsal arka plana rağmen, mutluluğu bütün zaman temelinde ele alan bir kavramsallaştırmanın yapılmamış olmasıdır. Bu ihtiyaçtan hareketle kişinin 3 zaman temelli yaşam öyküsünü bir bütün olarak gören ve belleğin çalı̧̧ma prensibini de hesaba katan tanımlamalar oluşmaya başlamıştır. Geçmiş yaşam olaylarını hatırlamadaki seçicilik yaşam hikâyesinin ve bellek içeriğinin zaman içerisinde değişimine işaret etmektedir. Bu ana unsurlardan hareketle, klasik ÖİO'un durağan kişilik ve dış dünyadan bağımsız, genetik duygulanım eğilimli yaklaşımlarından farklı olarak, öyküsel perspektifte dinamik ve 
değişebilen bir ÖİO teorisinden bahsetmek mümkündür (Şimşek ve Kocayörük, 2013).

Şimşek'e göre (2009) insan hayatı geçmiş ve geleceğin arasında yapılandırılmış ve hikâye formunda oluşturulmuştur. Buradan hareketle birey geçmişe dair hissiyatı ve geleceğe bakışı ile kendi yaşam öyküsünü oluşturmaktadır. Ontolojik iyi oluş (OİO) kavramı öyküsel paradigma ekseninde böylece yer bulmuştur. Geçmiş ve gelecek değerlendirmeleri kişinin bugünkü iyi oluş halini belirlemektedir (Şimşek, 2009). Sonuç olarak ontolojik iyi oluş, kişinin kendi yaşamına amaçlılık çerçevesi içerisinde öyküsel olarak geçmiş, şimdiki ve gelecek zaman bileşenlerini içererek geçici bir açıyla yarattığı ve sürdürdüğü bir yaşam projesine değinmektedir (Kocayörük ve ark., 2018)

Sevgi, yakınlık, cinsellik ziyadesiyle karmaşık konulardır. Evlilik ya da ilişki gibi bağlılığın temel olduğu ilişkilerde ise cinsellik daha şiddetli ve temel bir konu haline gelir. Tam da bu bağlamda kişilerin cinselliklerine dair atıfları aslında bir sürecin göstergesi gibi ele alınabilir. Çünkü cinsellik yakınlığın ve birlikteliğin en zirve noktası gibidir ve bu yakınlığı asla sadece cinsel birliktelik oluşturmaz. Cinsel doyuma bakıldığında burada kişi veya kişilerin bütün yakınlık, ilgi, bakım alma ve bakım verme serencamı ve bütün bu olup bitenin, kişi özelindeki anlamı ve hikâyesi bulunabilecektir.

Bireyin cinsiyeti ve yaşı, cinsellikle ilgili tecrübesi, toplumsal ilişkileri, kültürel etkenler, sosyal koşullar, cinsel doyumla ilgili olarak bireysel farklılıklara neden olmaktadır. Cinsel doyum kişilerin cinsel yaşantıları hakkında olumlu ya da olumsuz olarak öznel değerlendirmelerini içermekle birlikte ilişki memnuniyeti, benlik değeri gibi değişkenler ile bağlantılı olup kişilerin evliliğindeki doyumun ve memnuniyetin en güçlü belirleyicilerinden biridir (Stephenson ve Meston, 2011).

Konuyla ilgili literatür incelendiğinde Larson (1988) evlilik doyumun en iyi tek yordayıcısının çiftlerin cinsel yaşamlarının kalitesi olduğunu belirtmektedir (Akt., Jones ve Nelson, 1997). Youn (2009)'a göre evlilikte cinsellik bakımından eşlerin birbirlerinin ihtiyaçlarına karşılık verip vermemeleri ile birlikte, bu ihtiyaçlarına nasıl karşllık verdikleri de bireylerin cinsel yaşamında önemli rol oynamaktadır. Trudel (2002) ise nedensellik anlamında evlilik işleyişi ve cinsel yaşam arasındaki ilişkiyi incelediği araştırmasında cinsel tutumlar ve evlilik işleyişi arasında anlamlı ilişkiler 
bulmuştur (Trudel, 2002). Bu araştırmalar çerçevesinde, eşlerin cinsel yaşamlarında tatmin yaşama düzeylerinin evlilik yaşamlarında ve doyumlarında önemli bir rol oynadığı söylenebilir. Dolayısıyla eşlerin cinsel yaşamlarındaki kalitenin arttırılması ve doyumun yükselmesine dair yapılacak çalışmalar ve bireylerin sahip olacakları tatmin edici bir cinsel yaşam, eşlerin aynı zamanda evliliklerinden alacakları doyumu da arttıracaktır.

Larson ve ark. (1998) evliliğin ilk yılında evlilik öncesi iletişimin, ilişki stabilitesinin ve benlik saygısının cinsel tatmin üzerindeki etkilerini anlamak için uzun süreli bir çalışma yürütmüştür. Bu çalışma, kadınların benlik saygısı, açık iletişimi ve ilişki stabilitesinin, erkeğin cinsel tatmininin en iyi yordayıcısı olduğunu ortaya koymuştur. Kadınların cinsel tatminini en iyi şekilde yordayan ise kendi öz saygıları, kendi açık iletişimleri ve eşlerinin empatik iletişimi olarak bulunmuştur. $\mathrm{Bu}$ araştırma sonucundan da anlaşılacağı üzere taraflar aynı evlilik ilişkisine dair farklı beklentiler ve bakış açılarına sahip olma eğilimindedirler. Dolayısıyla kadınlar ve kocaları birbirlerinin algılarını, davranışlarını ve tatminlerini etkilemektedir. Bundan dolayı bir evlilik içerisinde cinsel tatminin doğasını tam olarak anlayabilmek için iki tarafı da anlamak ciddi önem taşımaktadır (Koçak, 2009).

Özetle bu çalışmanın yönelimi belirlenirken, bağlanma stillerinin cinsel doyum üzerindeki etkisinin araştırılmasında, bireyin yaşam projesinin yani ontolojik iyi oluşunun (OİO), geçmiş, şimdi ve gelecek tasavvurlarının evlilik doyumunun en önemli belirleyicilerinden olan cinsel doyumüzerinde etkili olduğu düşünülmüştür. Bu bağlamda, bağlanma stillerinin cinsel doyum üzerindeki etkisi bilinmektedir ancak analiz sürecine OİO değişkeninin girmesi ile yeni nedensellik sonuçları elde edilmiştir. Bu inceleme çift veri üzerinden gerçekleştirilmiştir. Bu durum bulguların çift ilişkisinin karşılıklılık üzerinden yorumlanmasını da sağlamaktadır.

\section{Araştırmanın Amacı ve Önemi}

Evlilik kişinin yaşamının tüm alanlarını etkileyen bir öneme sahiptir. Ruh ve beden sağlığını etkilediğine dair alanyazında çok sayıda araştırma bulunmaktadır. (Scheidler, 2008; Williams, 2003, Coyne ve ark. 2001, 
McCarthy 1997). Araştırma bulgularına göre mutluluğu ve yaşam doyumunu etkileyen en önemli faktörün yakınlarımızla ve en başta da eşlerimizle kurduğumuz güçlü, yakın ve tatmin edici bağların oluşturduğu bulgusuna ulaşılmıştır. Yetişkinlikte kurulan yakın ilişkilerin temelleri incelendiğinde ise, yaşamın erken dönemlerinde ebeveynlerle kurulan yakın ilişkilerin belirleyici olduğu tespit edilmiştir. (Banse, 2004; Feeney ve Hohaus, 2001;Feeney, 1999). İyi ve mutlu edici yaşamın sırrı mutlu ilişkilerde görünmektedir (Waldvinger, 2015). Evliliğin temel amacı ortak bir yaşamın paylaşılması, aşk ya da sevgi şeklinde tanımlanan bağın olmasıyla birlikte, cinsel doyumun elde edilmesidir (McCarthy, 1997). Dolayısıyla tatmin edici bir cinsel doyum, mutlu bir evliliğin temel göstergelerinden biri durumuna gelmektedir. Cinselliğin tatmin edici düzeyde yaşanıyor olması bir evlilik için hem yakın ilişkinin göstergesi hem de mutlu birlikteliğin besleyicisidir. Dolayısıyla iyi bir evliliğin temellerini ebeveynlerle kurulan ilk bağlanma ilişkileri belirlerken, evlilikte yaşanan tatmin edici cinsellik de evlilik doyumunun temel göstergelerinden biri olarak karşımıza çıkmaktadır.

Bağlanma stilleri bütün etkililiği ile birlikte değişime de dirençli yapılardır. Bu bağlamda araştırma çerçevesinde, cinsel doyum puanlarını arttırıcı başka bir değişken olan ontolojik iyi oluş kavramı sürece dâhil edilmek üzere ele alınmıştır. Ontolojik iyi oluş giriş bölümünde de ele alındığı üzere, kişinin bir proje olarak yaşamında geçmişi, şimdiyi ve geleceği nasıl değerlendirdiğini keşfetmek için ortaya atılmış bir kavramdır (Şimşek, 2009). Bağlanma stilleri ile cinsel doyum ilişkisi daha önceki birçok araştırmada bulgulanmıştır. Bu bağlamda kişilerin yaşam öykülerini sembolize ediş biçimlerinin, yani yaşam projelerinin bu iki değişkenle yakın ilişkide olacağı öngörülmüştür. Bu öngörüden hareketle araştırmanın modeli "bağlanma stillerin ve ontolojik iyi oluşun cinsel doyuma etkisi" ni ölçmek üzere kurgulanmıştır.

Yetişkin bağlanma stillerinin geçmişten getirilerek şimdiyi ve geleceği şekillendiren yapılar olduğu göz önünde bulundurulduğunda, ontolojik iyi oluşun bağlanma stilleri üzerinden cinsel doyumu arttırıcı rolünün araştırma neticesinde ortaya koyulacağı düşünülmektedir. Buradan hareketle araştırmanın, psikoterapi alanında yeni ve bağlanma stilleri gibi görece dirençli yapılarla çalışmada kolaylaştırıcı modeller sağlayacağı düşünülmektedir. 


\section{Yöntem}

\section{Örneklem}

Çalışmanın örneklemi, araştırmaya katılmaya gönüllü çiftlerden oluşmaktadır. Uygulama sırasında çiftlerden ölçme araçlarında yer alan soruları cevaplamaları istenmiş ve istatistiksel analiz, elde edilen veriler üzerinden yapılmıştır. Araştırmacı uygulamayı şahsen yapmıştır. Çiftlerden birlikte fakat birbirlerinin cevaplarını görmeyecek şekilde oturmaları istenmiştir. Doğru ve güvenilir bilgi alınabilmesi amacıyla ve çift puanları analiz edileceğinden kapalı zarf usulü kullanılmıştır. Kişilerden kimlik bilgileri kesinlikle istenmemiştir. Çiftlere bu çalışmanın amacı anlatılarak, elde edilecek verilerin tamamen gizli kalacağı ve çalışma dışında herhangi bir şekilde kullanılmayacağı bu nedenle doğru bilgi vermelerinin önemli olduğu açıklanmıştır. Örneklem 215 çift ile sınırlandırılmıştır. Örneklem büyüklügünün belirlenmesinde; evrenin özelliği, evrendeki elemanların dağılımı, temsil yeterliliği, maliyet, zaman, araştırmanın özelliği ve veri analizi gereklilikleri dikkate alınmıştır (Karasar, 2016). 21 - 63 yaş arasındaki ulaşılabilirlik ve gönüllülük ölçütlerini karşılayan çiftlerden seçilen grup, normal popülasyondan rastgele olarak belirlenmiştir. Araştırma mevcut durumu tespit etmeyi hedeflediği için, betimsel araştırma yöntemlerinden ilişkisel tarama modeli kullanılmıştır.

\section{Veri Toplama Araçları}

Bilgi Formu: Literatüre dayanılarak araştırmacı tarafından oluşturulmuştur. Araştırmaya katılan çiftlerin demografik ve genel sağlık durumları ile ilgili bilgilerin alınması amaçlanmıştır. Form katılımcı bilgilerinin alınabilmesine dair 10 soru içermektedir.

Yakın Ilişsilerde Yaşantılar Envanteri II (YIYYE II): Fraley ve Shaver (2000), Brennan, Clark ve Shaverin geliştirmiş olduğu YIYE'nin madde tepki kuramını kullanarak yeni analiz sonucunda Yakın İlişkilerde Yaşantılar Envanteri II'yi (YIYE II) geliştirmişlerdir. Yakın İlişkilerde Yaşantılar Envanteri'nin (YIYE II) Türkçeye uyarlama çalışmaları Selçuk, Günaydın, Sümer ve Uysal (2005) tarafından yapılmıştır. 
Yaşam Projesi Ölçeği (YPÖ): Şimşek (2009) tarafından, bu perspektife uygun olarak geliştirilen Yaşam Projesi Ölçeği, pozitif ve negatif ruh sağlı̆̆ alanlarında anlamlı sonuçlar vermiş, iç motivasyon ve psikolojik iyi oluş kavramlarıyla ilişkili bulunmuştur (Şimşek, 2009). "Geçmiş", "Şimdi" ve "Gelecek" şeklinde gruplanan ölçek toplam 24 soru maddesi içerir. Ölçeğin "nothingness" (hiçlik), "activation" (aktivite), "regret" (pişmanlık) ve "hope" (umut) olmak üzere dört alt boyutu vardır.

Golombok- Rust Cinsel Doyum Ölçeği (GRCDÖ - Kadın / Erkek Formu): Rust ve Golombok (1986) tarafından cinsel ilişkinin niteliği ve cinsel işlev bozukluklarını incelemeye yönelik geliştirilen ölçüm aracı düzenli bir eşi olan heteroseksüel birey ya da çiftlere uygulanmaktadır. Golombok Rust Cinsel Doyum Ölçeğinin Türkçeye uyarlama çalışmaları Tugrul, Öztan ve Kabakçı (1993) tarafından yapılmıştır.

\section{Sinirlılıklar}

$\mathrm{Bu}$ çalışma örneklemi çerçevesinde bazı sınırlılıklar taşımaktadır. Araştırmanın verileri, Kişisel Bilgi Formu, Yakın İlişkilerde Yaşantılar Envanteri II, Yaşam Projesi Ölçeği, Golombok-Rust Cinsel Doyum Ölçeğinden (kadın/erkek soru formu) alınan bilgilerle sınırlıdır. Araştırma verileri; Türkiye'nin çeşitli kentlerinde yaşayan (İstanbul, Ankara, İzmir, Bursa, Eskişehir, Elazığ, Samsun, Ordu, Düzce, Kocaeli), tesadüfi olarak belirlenen, katılmaya gönüllü evli çiftlerin doğru cevap verdikleri varsayılarak elde edilmiştir. Araştırma verileri kapalı zarf içinde şahsen uygulanarak elde edilmiş olması ile sınırlıdır. Ayrıca veriler 21 - 63 yaş arası evli çiftlerin cevapları ile sınırlandırılmıştır. Araştırma bulguları 215 çiftten alınan cevaplarla sinırlidır.

\section{İşlem}

Katılımcıların demografik özelliklerinin belirlenebilmesi için betimsel istatistik sonuçlarına ve cinsiyete göre gruplar arası farklılık olup olmadığını belirlemek için ki-kare testi sonuçlarına yer verilmiştir. Çalışmanın amacı doğrultusunda, öncelikli olarak bağlanma stilleri, ontolojik iyi oluş 
ve cinsel doyum arasındaki ilişkileri ortaya koymak amacıyla Pearson momentler çarpımı korelasyon analizi yapılmıştır. Bağımsız değişkenlerin cinsel doyumda açıklanan varyansa istatistiksel olarak anlamlı katkısı olup olmadığını, katkısı varsa yordama düzeyini belirleyebilmek amacıyla çoklu doğrusal regresyon analizi yapılmıştır. Verilerin analizi sırasında SPSS 25.0 programı kullanılmıştır.

\section{Bulgular}

\section{Katılımcıların Tanımlayıcı ve Betimleyici Analizleri}

Tablo 1'de 215 çifte ait demografik özellikler ve anlamlılık testi yer almaktadır. Yaşları 21 ile 63 arasında değişen katılımcılar cinsiyete göre incelendiğinde, annenin hayatta olup olmama $(X 2(1)=6.76, p<.01)$ ve psikiyatrik tanı alıp almama $(X 2(1)=5.66, p<.05)$ durumuna göre anlamlı farklılık göstermektedir. Demografik bilgi formunda yer alan diğer sorulara göre cinsiyete göre gruplar arası anlamlı farklılık bulunmamaktadır ( $>>05)$.

Tablo 1. Araştırmaya katılan bireylere ait tanımlayıcı istatistikler

\begin{tabular}{|c|c|c|c|c|c|c|}
\hline \multirow[t]{2}{*}{ Değişkenler } & & \multicolumn{2}{|c|}{ Kadın } & \multicolumn{2}{|c|}{ Erkek } & \multirow[t]{2}{*}{$\mathbf{X}^{2}$} \\
\hline & & $\bar{n}$ & $\%$ & $n$ & $\%$ & \\
\hline \multirow[t]{4}{*}{ Yaş } & $21-30 ; 24-33$ aras1 & 104 & 48.4 & 100 & 46.5 & 1.13 \\
\hline & $31-40 ; 34-43$ aras 1 & 76 & 35.3 & 72 & 33.5 & \\
\hline & $41-50 ; 44-53$ aras 1 & 28 & 13 & 33 & 15.3 & \\
\hline & $51-60 ; 54-63$ aras1 & 7 & 3.3 & 10 & 4.7 & \\
\hline \multirow[t]{4}{*}{ Eğitim Durumu } & Lise & 66 & 30.7 & 67 & 31.2 & 6.49 \\
\hline & Üniversite & 114 & 53 & 128 & 59.5 & \\
\hline & Yüksek lisans & 31 & 14.4 & 15 & 7 & \\
\hline & Doktora & 4 & 1.9 & 5 & 2.3 & \\
\hline \multirow[t]{3}{*}{ Evlilik Biçimi } & Flört & 162 & 75.3 & 161 & 74.9 & .02 \\
\hline & Görücü & 39 & 18.1 & 40 & 18.6 & \\
\hline & Diğer & 14 & 6.5 & 14 & 6.5 & \\
\hline \multirow[t]{5}{*}{ Çocuk Sayısı } & 0 & 96 & 44.7 & 96 & 44.7 & .02 \\
\hline & 1 & 53 & 24.7 & 53 & 24.7 & \\
\hline & 2 & 47 & 21.9 & 47 & 21.9 & \\
\hline & 3 & 15 & 7 & 15 & 7 & \\
\hline & 4 ve fazlası & 4 & 1.9 & 4 & 1.9 & \\
\hline \multirow[t]{2}{*}{ Anneniz Hayatta Mı? } & Sağ & 202 & 94 & 186 & 86.5 & $6.76^{* *}$ \\
\hline & Ölü & 13 & 6 & 29 & 13.5 & \\
\hline
\end{tabular}




\begin{tabular}{lllllll}
\hline Babanız Hayatta Mı? & Sağ & 173 & 80.5 & 169 & 78.6 & .23 \\
& Ölü & 42 & 19.5 & 46 & 21.4 & \\
\hline Kronik Hastalığınız Var Mı? & Var & 30 & 14 & 21 & 9.8 & 1.80 \\
& Yok & 185 & 86 & 194 & 90.2 & \\
\hline Eşinizin Kronik Hastalı̆̆ı Var Mı? & Var & 21 & 9.8 & 28 & 13 & 1.13 \\
& Yok & 194 & 90.2 & 187 & 87 & \\
\hline \multirow{2}{*}{ Hiç Psikiyatrik Tanı Aldınız Mı? } & Evet & 26 & 12.1 & 12 & 5.6 & $5.66^{*}$ \\
& Hayır & 189 & 87.9 & 203 & 94.4 & \\
\hline \multirow{2}{*}{ Eşiniz Psikiyatrik Tanı Aldı Mı? } & Evet & 13 & 6 & 24 & 11.2 & \multirow{2}{*}{3.58} \\
& Hayır & 202 & 94 & 191 & 88.8 & \\
\hline
\end{tabular}

Tüm ölçekler ve alt ölçeklerden alınan puanların ortalamalarının, yapılan istatistiksel analiz sonucu normal dağılım gösterdiği saptanmıştır. Verilere dair betimleyici istatistikler, basıklık ve çarpıklık katsayıları Tablo 2'de ayrıntılı biçimde yer almaktadır.

Tablo 1. Ölçeklere ait betimleyici istatistikler

\begin{tabular}{llllll}
\hline Ölçek & N & $\overline{\mathbf{X}}$ & SS & Basıklık & $\begin{array}{l}\text { Çarpık- } \\
\text { lik }\end{array}$ \\
\hline Yaşam Projesi Ölçeği & 214 & 117,73 & 15,49 & 1,47 & 0,50 \\
Pişmanlık & 215 & 28,79 & 8,43 & 0,90 & 0,71 \\
Aktivasyon & 214 & 29,21 & 7,32 & $-0,36$ & 0,20 \\
Hiçlik & 215 & 18,88 & 6,97 & 4,06 & 1,84 \\
Umut & 215 & 40,87 & 9,91 & $-0,41$ & $-0,17$ \\
Yakın İlişkilerde Yaşantılar Envanteri - II & 215 & 176,47 & 31,86 & $-0,62$ & $-0,16$ \\
Kaçınmacı Bağlanma & 215 & 91,39 & 21,68 & $-0,51$ & $-0,17$ \\
Kaygılı Bağlanma & 215 & 85,07 & 15,63 & 0,12 & 0,20 \\
Golombok - Rust Cinsel Doyum Ölçeği & 215 & 39,42 & 20,26 & $-0,03$ & 0,57 \\
İlişkinin Sıklığ1 & 215 & 6,70 & 3,36 & $-0,13$ & 0,14 \\
İletişim & 215 & 6,00 & 3,73 & $-0,41$ & 0,44 \\
Doyum & 215 & 10,01 & 5,85 & 0,53 & 0,65 \\
Kaçınma & 215 & 6,40 & 5,21 & 0,80 & 1,03 \\
Dokunma & 215 & 10,01 & 5,85 & 0,53 & 0,65 \\
\hline
\end{tabular}

\section{Ölçekler ve Alt Ölçekler Arası Korelasyonlar}

Ölçeklerin ve alt ölçeklerin birbirleri arasındaki ilişkiler Tablo 3'de sunulmuştur. YİYE-II'nin kaygılı bağlanma alt boyutu ile GRDCÖ'nün ilişkinin sıklığı alt boyutu arasında anlamlı düzeyde ilişki bulunmamaktadır. Araştırmada kullanılan diğer ölçeklerin toplam puanları ve alt boyutları arasında anlamlı düzeyde ilişki bulunmaktadır $(\mathrm{p}<.01)$. 
Tablo 3. Ölçekler ve alt ölçekler arası korelasyonlar

\begin{tabular}{|c|c|c|c|c|c|c|c|c|c|c|c|c|c|c|}
\hline Ölçekler & 1 & 2 & 3 & 4 & 5 & 6 & 7 & 8 & 9 & 10 & 11 & 12 & 13 & 14 \\
\hline 1.YPÖ1 & - & & & & & & & & & & & & & \\
\hline 2.Pişmanlık & $-.63^{*}$ & - & & & & & & & & & & & & \\
\hline 3.Aktivasyon & $.78^{*}$ & $-.48^{*}$ & - & & & & & & & & & & & \\
\hline 4.Hiçlik & $-.72^{*}$ & $.54^{*}$ & $-.29^{*}$ & - & & & & & & & & & & \\
\hline 5.Umut & $.79^{*}$ & $-.41^{*}$ & $.68^{*}$ & $-.27^{*}$ & - & & & & & & & & & \\
\hline 6.YİYE-II² & $-.46^{*}$ & $.40^{*}$ & $-.40^{*}$ & $.37^{*}$ & $-.36^{*}$ & - & & & & & & & & \\
\hline $\begin{array}{l}\text { 7.Kaçınmacı } \\
\text { Bağlanma }\end{array}$ & $-.45^{*}$ & $.38^{*}$ & $.40^{*}$ & $.34^{*}$ & $-.38^{*}$ & $.90^{*}$ & - & & & & & & & \\
\hline $\begin{array}{l}\text { 8.Kaygilı } \\
\text { Bağlanma }\end{array}$ & $-.32^{*}$ & $.29^{*}$ & $-.27^{*}$ & $.28^{*}$ & $-.20^{*}$ & $.79^{*}$ & $.44^{*}$ & - & & & & & & \\
\hline 9.GRCDÖ3 & $-.48^{*}$ & $.36^{*}$ & $-.38^{*}$ & $.37^{*}$ & $-.41^{*}$ & $.53^{*}$ & $.58^{*}$ & $.28^{*}$ & - & & & & & \\
\hline $\begin{array}{l}\text { 10.İlişkinin } \\
\text { Sıklığ1 }\end{array}$ & $-.30^{*}$ & $.25^{*}$ & $-.25^{*}$ & $.23^{*}$ & $-.22^{*}$ & $.27^{*}$ & $.35^{*}$ & .06 & $.71^{*}$ & - & & & & \\
\hline 11.İletişim & $-.40^{*}$ & $.27^{*}$ & $-.35^{*}$ & $.20^{*}$ & $-.43^{*}$ & $.47^{*}$ & $.55^{*}$ & $.21^{*}$ & $.72^{*}$ & $.46^{*}$ & - & & & \\
\hline 12.Doyum & $-.46^{*}$ & $.34^{*}$ & $-.37^{*}$ & $.35^{*}$ & $-.38^{*}$ & ${ }^{*} 48^{*}$ & $.53^{*}$ & $.24^{*}$ & $.95^{*}$ & $.58^{*}$ & $.59^{*}$ & - & & \\
\hline 13.Kaçınma & $-.36^{*}$ & $.25^{*}$ & $-.25^{*}$ & $.35^{*}$ & $-.26^{*}$ & $.48^{*}$ & $.46^{*}$ & $.35^{*}$ & $.79^{*}$ & $.46^{*}$ & $.47^{*}$ & $.64^{*}$ & - & \\
\hline 14.Dokunma & $-.31^{*}$ & $.34^{*}$ & $-.37^{*}$ & $.35^{*}$ & $-.39^{*}$ & $.48^{*}$ & $.53^{*}$ & $.24^{*}$ & $.95^{*}$ & $.58^{*}$ & $.59^{*}$ & $.99^{*}$ & $.64^{*}$ & - \\
\hline
\end{tabular}

1Yaşam Projesi Ölçeği; ${ }^{2}$ Yakın İlişkilerde Yaşantılar Envanteri-II; ${ }^{3}$ Golombok - Rust Cinsel Doyum Ölçeğ $i^{*} p<.01$

\section{Çoklu Doğrusal Regresyon Analizi}

Tablo 4'e göre yakın ilişkilerde yaşantılar envanterinin alt boyutları ile yaşam projesi ölçeğinin alt boyutlarının cinsel doyumu açıklama gücünü belirlemek için yapılan çoklu doğrusal regresyon analizi sonuçlarına göre kaçınmacı ve kaygılı bağlanma ile doyum arasındaki çoklu ilişki yüksek düzey $(\mathrm{R}=.57)$ ve açıklama oranı \%32'dir. Kurulan bu çoklu regresyon modeli istatistiksel olarak anlamlıdır $(\mathrm{F}(2,211)=51.55, \mathrm{p}<.001)$. Kaçınmacı bağlanma, kaygılı bağlanma, pişmanlık, aktivasyon, hiçlik ve umut ile doyum arasındaki çoklu ilişki yüksektir $(\mathrm{R}=.63)$ ve açıklama oranı \%38' dir. Kurulan bu çoklu regresyon modeli istatistiksel olarak anlamlıdır $(\mathrm{F}(6,207)=22.33, \mathrm{p}<.001)$. Parametreler incelendiğinde, standardize edilmiş regresyon katsayına göre yordayıcı değişkenlerin, cinsel doyum yordanan değişkeni üzerindeki önem sırasının kaçınmacı bağlanma $(\beta=.44, t=6.75, p<.001) ; \quad$ hiçlik $\quad(\beta=.16, t=2.39, p<.05) ; \quad$ umut $\quad(\beta=-15, t=-$ $1.96, \mathrm{p}<.05)$; aktivasyon $(\beta=-.06, \mathrm{t}=-.72, \mathrm{p}>.05)$; kaygilı bağlanma $(\beta=-.02, \mathrm{t}=-$ $.33, p>.05)$ ve pişmanlık $(\beta=.02, t=.24, p>.05)$ olduğu görülmektedir. Kaçınmacı bağlanma, hiçlik ve umut bağımsız değişkenlerinin cinsel doyumun anlamlı yordayıcıları olduğu söylenebilir. 
Tablo 4. Bă̆ımsız değişkenlerin cinsel doyum puanlarını yordamasına ait sonuçlar

\begin{tabular}{|c|c|c|c|c|c|c|c|c|}
\hline $\begin{array}{l}\text { Bağımsız } \\
\text { Değişkenler }\end{array}$ & $\beta$ & $\begin{array}{l}\text { Standart } \\
\text { Hata }\end{array}$ & $\begin{array}{l}\text { Std. } \\
\beta\end{array}$ & $\mathrm{R}$ & $\begin{array}{l}\text { Düzeltilmiş } \\
\mathrm{R}^{2}\end{array}$ & $\Delta \mathrm{R}^{2}$ & $\mathrm{~F}$ & $\mathrm{t}$ \\
\hline Sabit & -11.02 & 6.78 & - & .57 & .32 & .33 & $51.55^{* *}$ & -1.63 \\
\hline Kaçınmacı & .53 & .06 & .56 & & & & & $9.00^{* *}$ \\
\hline Kaygil1 & .03 & .08 & .02 & & & & & .32 \\
\hline Sabit & 10.96 & 11.37 & - & .63 & .38 & .07 & $22.33^{* *}$ & .96 \\
\hline Kaçınmacı & .42 & .06 & .44 & & & & & $6.75^{* *}$ \\
\hline Kaygill & -.03 & .08 & -.02 & & & & & -.33 \\
\hline Pişmanlık & .04 & .17 & .02 & & & & & .24 \\
\hline Aktivasyon & -.16 & .22 & -.06 & & & & & -.72 \\
\hline Hiçlik & .46 & .19 & .16 & & & & & $2.39^{*}$ \\
\hline Umut & -.30 & .15 & -.15 & & & & & $-1.96^{*}$ \\
\hline
\end{tabular}

\section{Tartışma ve Sonuç}

Araştırma kapsamında gerçekleştirilen korelasyon ve regresyon analizleri, çiftlerden elde edilen puanların toplamı üzerinden yapılmıştır. Çalışmanın psikoterapi alanında ve bağlanma stilleri gibi görece dirençli yapılarla çalışmada yeni ve kolaylaştırıcı modeller için yol açıcı sonuçlar getireceği düşünülmüştür. Analizlerin ardından bu varsayımın doğrulandığı söylenebilir.

Bağlanma stillerinin cinsel doyuma etkisi ile ilgili literatür incelendiğinde; güvenli bağlanan kişilerin daha doyurucu cinsel ilişkisi olduğu ve bunun getirisi olarak da evlilik doyumlarının yüksek olduğu (Butzer ve Campbell, 2008), buna karşın kaygılı ve kaçınmacı bağlanan kişilerin daha az cinsel tatmin yaşayıp düşük cinsel doyuma sahip oldukları görülmüştür (Clymer, Ray, Trepper ve Pierce, 2006). Ayatollahi (2014), kaçınmacı bağlanma stili olan kişilerin daha fazla cinsel doyum yaşadığını kaygılı bağlanma stiline sahip olan kişilerin ise daha az cinsel doyum yaşadıklarını tespit etmiştir. Impett, Gordon ve Strachman (2008) tarafından kaygılı bağlanan kişinin cinsel partnerini memnun etmek için cinsel ilişkiye girdiği, kaçınmacı bağlanan kişilerin ise ilişkinin getireceği olumsuz sonuçlardan kaçınmak için aşklarını sadece cinsel ilişki ile ifade ettikleri belirlenmiştir. Bu çalışmada da benzer biçimde kaçınmacı stilin, YPÖ boyutlarından hiçlikle birlikte cinsellikte doyumun anlamlı yordayıcısı olduğu tespit edilmiştir. Hiçliğe dair elde edilen istatistiksel 
bulgu, varoluşsal anlamda felsefi alanyazın üzerinden, tartışma bölümünün son kısmında ele alınmıştır.

Yapılan çalışmanın kadın örneklemindeki korelasyon analizi bulgularına bakıldığında, kadınların kaygılı bağlanmasının kendi cinsel doyum alt faktörlerinden "kaçınma" ve "doyum" ile güçlü korelasyon gösterirken, "iletişim", "vajinismus", "anorgazmi" ile pozitif yönlü korelasyon görülmüştür. Buna göre kadının kaygılı bağlanması arttıkça yukarıdaki maddelerde de artış görülmektedir. Kadının kaçıngan bağlanmasının kendi cinsel doyum alt faktörlerinden "dokunma", "doyum", "iletişim", "anorgazmi", "kaçınma", "sıklık", "vajinismus" arasında pozitif yönlü güçlü korelasyon bulunmuştur. Buna göre kadının kaçıngan bağlanmasında artışın olması yukarıdaki maddelerde de artışa neden olmaktadır. Olumsuz boyut puanlarında artışın olması cinsel sorunların arttığını ve doyumun azaldığını göstermektedir.

Yapılan analizler neticesinde elde edilen bulguların alanyazın ile örtüşür nitelikte olduğu görülmektedir. Özellikle YPÖ sürece dâhil edildiğinde, yordama puanlarının artıyor olması ile birlikte, adı gecen ölçeğin iki boyutunun; yani umut ve hiçlik boyutlarının, özellikle bu araştırmanın hipotezi ve modeli çerçevesinde ön plana çıktığı ve varyansın bu boyutlar üzerinden daha fazla arttı̆̆ bulgulanmıştır. Çalışmanın bulgularına göre cinsel doyum ile YPÖ alt boyutu olan umut değişkeni arasında orta düzey ters yönde ilişki bulunduğu gözlenmektedir. Bu bulgu konunun felsefi arka planının yanı sıra, umut değişkenine dair yapılan bazı araştırmalarda da çalışma bulgularıyla paralellik arz etmektedir. Snyder ve diğerleri (1991) umudun, stres sürecinde ve başa çıkmada önemli rol oynadığını, Irving ve diğerleri (2004) ise umutlu düşüncenin başa çıkma mekanizmalarını aktif biçimde kullanmayı sağladığını ifade etmişlerdir (Tarhan ve Bacanl1 2016). Felsefi alanyazında umudun, insandaki varoluş duygusunu oluşturduğu görülür. Kişi umut yoluyla ötekine açlmaya ve onunla tüm samimiyetiyle bir ilişki kurmaya hazır olduğunu gösterebileceği gibi, umutsuzluğu ile birlikte kendi beni hatırına, ben-olmayana kapılarını kapatarak, güven duygusundan yoksun şekilde, çaresizliğe düşerek kendisini gerçekleştirmekten vazgeçebilir de (Renaux, 1994; Koç, 2008). Buradan hareketle, umudun azalması ile birlikte cinsel doyumda artış oluşması başka bir değişle iletişimin azalmış olmasının umudun artması 
demek olması, bizi cinsel doyumun, bir iletişim ve yaşamda umudu arttırma yolu olduğu fikrine sevk edebilir. Denilebilir ki; adına sevgi denilen cinsel ilişki, daha çok nihai birliktelik deneyimini dışa vurmanın bir yolu olarak görülmelidir. (Frankl, 2013). Zira Robert C. Solomon'a göre cinsel arzunun sonu ya da hedefi kişiler arası iletişimdir (Shaffer, 2015). Tam da burada cinsel doyumun yordayıcı değişkenlerinden birinin ters orantılı olarak umutken, diğerinin doğru orantılı olarak kaçınmacı bağlanma olması, kaçınmacı bağlanan bireylerin daha fazla cinsel ilişki arayışında oluşları ve yakınlığı bu şekilde sağlama yoluna gittikleriyle (Ayatollahi, 2013) örtüşüyor görünmektedir ve kaçınmacı bağlanan kişiler cinsel ilişkiyi aşklarını ifade etmek için kullanmaktadırlar (Impett ve ark., 2008).

Şimşek ve Kocayörük (2012)' ün yaptıkları YPÖ faktör analizleri sonucunda, "hiçlik -nothingness" ad1 verilen varoluşsal bir boyut ortaya çıkmıştır ki bu da hiçbir ilerlemenin mümkün olmadığı bir durumda kendini bulmayı ifade eder. Hiçliğe ve cinsel doyum ile ilişkisine dair sonuçlar felsefi alanyazın üzerinden tartışılacaktır. Klinik uygulama içerisinde böylesine ontolojik kavrayış ve sorgulama, genel anlamda Aristoteles'ten günümüze kadar tüm felsefe tarihini, özelde de varoluşçuluk gibi bir alanı ve konuyla ilgili inanılmaz derecede büyük bir alanyazını önümüze sermektedir.

Heiddeger'e göre "varlığın bütünlüğü ile inkarı" olan hiçliğin ne olduğunu anlamak yeni bir anlam yaratmak için varolanın bütünlüğü ile yüzleşmekten geçer. Yaşamda kişisel anlama sahip olmak mutluluk için hareket noktasıdır. Amaç bir göreve veya bir hedefe yönelme olarak tanımlanırken, anlam, bu yönelmeyi ve tutarlılığı da kapsayan daha derin bir varoluşsal tanıma sahiptir (Frankl, 1984; Reker, 1992). Heiddeger'e göre varolanın bütünlügüne dâhil olmanın ve anlam bulmanın birinci aşaması olarak ifade edebileceğimiz şey iç daralmasıdır. Frankle (2013) ise, buna insanların yoğun ve oyalayıcı uğraşlarından sıyrılıp kendi içlerindeki boşluk belirginleştiği zaman, yaşamlarının anlamdan ve başka bir deyişle aslında içerikten yoksun olduğunu fark etmeleridir der ve nevrozu işaret eder. Yine Frankle'ye göre engellenen bu anlam istemi, bir güç istemi ile temsili bir yoldan dengelenir. Bu durumlarda engellenen anlam çabasının yerine haz devreye girecektir. Varoluşsal engellenmenin birçok durumda cinsel dengeleme ile sonuçlanmasının nedeni budur. $\mathrm{Bu}$ tür durumlarda, cinsel libidonun varoluşsal boşlukta serpilip yayıldığını 
gözlemleyebiliriz (Frankle, 2013). Csikszenmihalyi'ye göre ise, aynı eşle sürekli ve devamlı birliktelik artık hazzı da sağlamaz. İnsan bir başka insanı gerçekten tanımaya ve anlamaya başladığında macera mümkün olur. Cinsellik de tıpkı hayatın diğer yönleri gibi, onu yönetme ve daha büyük bir karmaşıklığa-anlama doğru geliştirme konusunda istekli olduğumuzda haz verebilir (Csikszenmihalyi, 2018, s.123). Buradan hareketle, sonuç olarak, çalışmanın bulguları ile felsefi ve klinik alanyazından elde edilen bulguların paralellik arz ettiği söylenebilir (Yıldırım, H.K. 2019).

\section{Öneriler}

Son dönemlerde evliliklerin çatışmalı hale gelmesi ve yüksek oranda sonlanması, yakın ilişkilerde bağlanma ve ilişki değişkenlerine dair araştırmaların önemini daha da artırmıştır. Bretherton (1992) bağlanma teorisinin kökenlerine dair yazdığı makalesinde, neratif terapinin temellerinin de dayandığı dile ve anlatıya dair ümidini "benim görüşüme göre içsel çalışma modellerinin gelişmesi, gerçekliğin sosyal yapısıyla ilgilenen, sağlıklı bakış açısına sahip, "söylemsel" ve "anlatımsal" yaklaşımlarla bağlantılı çalışmalar yapılmasına bağlıdır." ifadelerine yer vermiştir. Bu çalışmanın odağında olan ontolojik iyi-oluş da, tanımı gereği, anlatı psikolojisi ile yakından ilişkilidir. Anlatım ya da hikâye, psikoloji için potansiyel olarak yararlı bir örgütlenme ilkesidir. OİO her bireyin, kendi hayatının "metin" inin yazarı olarak bir anlatıya sahip olduğunu göstermektedir. (Şimşek, 2009). Bu bağlamda çalışmanın bulguları, bağlanma stilleri gibi görece daha dirençli yapılarla çalışan birey ve çift danışmanlarına kolaylaştırıcı bir yol sunabilecektir. Ontolojik iyi oluşun üzerine kurgulandığ1 zaman perspektifi ve kişinin yaşam hikayesi ile çalışan neratif- öyküsel terapi bağlamında oluşturulacak müdahale programlarına ihtiyaç duyulmaktadır. Bu çalışmanın ardılı olacak uygulama araştırmaları daha net sonuçlar alınmasını sağlayacaktır.

Kişilerin evlilik projelerinin cinsel doyum üzerindeki belirleyiciliğinin yüksek olduğu düşünülmektedir. Daha yüksek varyans elde edilip edilemeyeceğinin sınanması için daha sonraki araştırmalarda evliliğin bir proje olarak ele alınıp, değişkenlere evlilik projesi üzerinden bakılması yerinde olacaktır. Sonraki çalışmalarda kadın ve erkek farklarına odaklanarak iki farklı örneklemin ihtiyaçlarına dair bulguların ortaya çıarılması daha 
etkili müdahale programları için katkı sağlayacaktır. İlgili alanyazın dikkate alındığında, örneğin duygusal boyutun yaşlı insanlar için daha önemli olabileceği, yaşamın bilişsel değerlendirmesinin gençler için daha önemli olduğu söylenebilir. Geçmiş, yaşamdaki anlam ve amaç ile ilgilendikleri göz önüne alındığında, yaşlılar için daha önemliyken, gençler içinse gelecek daha önemli olabilir (Şimşek, 2009). Dolayısıyla yaş farklarına odaklanarak oluşturulan çalışmalar farklı sonuçları ortaya koyma açısından önerilmektedir. 
EXTENDED ABSTRACT

\title{
In Married Couples Attachment Styles' and Ontological Well-being's Effect on Sexual Satisfaction
}

\author{
H. Kübra Yılmaztürk Y1ldırım
}

Samsun University

Human's desire for relationship has meanings beyond the physical dimension. If this desire is in the emotional dimension, it is called attachment. Where a child encounters separation and loss occurs in the personality of the first caregiver. The bond between the newborn and the caregiver is not only a bond of love, but it can be said that it is a structure that will contribute to the development of the baby in cognitive, emotional, social and many other areas and will follow her in his close relationships throughout her life. Although the concepts of attachment and sexuality have their own activation area but these two concepts are not independent of each other. When the literature on the subject is examined, it is possible to say that the foundations of the individual's relationship with his sexual partner and sexual delivery are based on early attachment relationships. In marriages and relationships, sexuality becomes a more intense and fundamental issue. Because sexuality is like the pinnacle of intimacy and togetherness, and this intimacy never only constitutes sexual intercourse. When looking at sexual satisfaction, it will be possible to find the personal meaning and story of all the closeness, attention, care-taking and care-giving of the person. For instance secure individuals are generally happier, more self-confident, and more understanding and supportive of their partner's mistakes in their romantic relationships. Studies also show that individuals with anxious attachment are defined as "who have both close and fulfilling needs, and distant and unpredictable sides" regarding their early life and family relationships. It has been observed that these adults over-praise their partners, idealize them, put them in an inaccessible place, worry about abandonment, obsess about sexual attraction, and exhibit a jealous and emotional ups and downs. Avoidants, on the other hand, avoid the relationship and intimacy, keep their expectations about the relationship 
low, however, they stay away from the relationship and behave coldly towards their partners rather than meeting the demands.

While determining the orientation of this study, in investigating the effect of attachment styles on sexual satisfaction, it was thought that the individual's life project, namely ontological well-being (OIO), past, present and future acceptances were effective on sexual satisfaction, which is one of the most important determinants of marital satisfaction. In this context, the effect of attachment styles on sexual satisfaction is known, but new causality results were obtained with the inclusion of the OIO variable in the analysis process.

In this study, married couples' attachment styles' and ontological wellbeing's effect on sexual satisfaction levels is investigated. In the study, while attachment styles' effect on sexual satisfaction is investigated, at the same time, it is aimed to reveal the effect of individual's life project i.e. ontological well-being and his concept of past, present and future on sexual satisfaction. In consequence, couples' attachment styles' effect on sexual satisfaction and then after the ontological wellbeing questionnaire has entered into the process, whether it has a statistically meaningful contribution to the variance on sexual satisfaction is investigated. Sample of the study is composed of randomly selected married couples. The questionnaires have been handed in sealed envelopes. The study is based on voluntariness. The sample is composed of 215 couples between the ages of 23-63.

In the study, Personal Information Form, Experiences in Close Relationships II Questionnaire (ECR-R), Golombok Rust Inventory of Sexual Satisfaction (female/male) and Ontological Wellbeing Scale (OWBS) are used. IBM SPSS Statistics 22.0 is used for statistical analyses when evaluating the findings reached through the data of this study. According to the results of the model created, it is found that married couples' attachment styles and wellbeing levels have an effect on their sexual satisfaction and also that certain sub-dimensions of these independent variables have a higher effect on sexual satisfaction. According to the results of the analyses based on total scores; it can be said that independent variables avoidant attachment and anxious attachment, which are ECR-R's sub-dimensions, are meaningful predictors of infrequency sub-dimension. It can be said that the independent variables, ECR-R's avoidant attachment sub-dimension and 
OWBS' hope sub-dimension, are meaningful predictors of GRISS' non-communication sub-dimension. It can be said that the independent variables, ECR-R's avoidant attachment sub-dimension and OWBS' nothingness subdimension are meaningful predictors of GRISS' dissatisfaction sub-dimension. It can be said that the independent variables, ECR-R's avoidant attachment and anxious attachment sub-dimensions and OWBS' nothingness subdimension are meaningful predictors of GRISS' avoidance sub-dimension. It can be said that the independent variables, ECR-R's attachment sub-dimension and OWBS' nothingness sub-dimensions are meaningful predictors of non-sensuality sub-dimension.

\section{Kaynakça / References}

Ayatollahi, M (2014). Cinsel doyumu yordayan demografik ve psikolojik değişkenlerin incelenmesi. Yüksek Lisans Tezi. Ankara: Ankara Üniversitesi Eğitim Bilimleri Enstitüsü

Banse, R. (2004). Adult attachment and marital satisfaction: Evidence for dyadic configuration effects. Journal of Social and Personal Relationships, 21(2), 273-282. https://doi.org/10.1177/0265407504041388

Bilgin, N. (2001). İnsan ilişkileri ve kimlik. 2. Baskı. İstanbul: Sistem Yayıncılık. Bowlby, J (1969/1982) Attachment and loss: Vol. 1, Attachment. New York: Basic Books.

Bowlby, J. (2012). Bağlanma. İstanbul: Pinhan Yayıncilık.

Bretherton,I. (1992). The origins of Attachment Theory: John Bowlby and Mary Ainsworth. Developmental Psychology, 28, 759-775. https://doi.org/10.1037/0012-1649.28.5.759

Butzer, B. Campbell, L (2008). Adult Attachment, sexual satisfaction, and relationship satisfaction: A study of married couples. Personal Relationships. 15, 141-154. https://doi.org/10.1111/j.1475-6811.2007.00189.x

Büyükşahin, A. (2006). Yakın ilişkilerde bağlanım: yatırım modelinin bağlanma stilleri ve bazı ilişkisel değişkenler yönünden incelenmesi. Doktora Tezi, Ankara Üniversitesi Sosyal Bilimler Enstitüsü, Ankara.

Coyne, J.C., Rohrbaugh, M. J., Shoham, V., sonnega, J. S., Nicklas, J. M., Cranford, J. A.(2001). Prognostic importance of marital quality for survival of congestive heart failure. The American Journal of Cardiology, 88(5), 526-529. doi: 10.1016/s0002-9149(01)01731-3 
Clymer, S. R., Ray, R. E., Trepper, T. S. ve Pierce, K. A. (2006). The relationship among romantic attachment style, conflict resolution style and sexual satisfaction. Journal of Couple and Relationship Therapy, 5, 71-89. https://doi.org/10.1300//398v05n01 04

Csikszenmihalyi, M (2018). Akış: Mutluluk bilimi. 3. Baskı. Ankara. Buzdağ1 Yayınevi.

Diehl, M., Elnick, A. B., Bourbeau, L. S., Labouvie-Vief, G. (1998). Adult attachment styles: Their relations to family context and personality. Jurnal of Personality and Social Psychology, 74(6), 1656-69. doi: 10.1037//0022-3514.74.6.1656

Fraley, R. C., Shaver, P. R. (2000). Adult romantic attachment: Theoretical developments, emerging controversies, and unanswered questions. Review of General Psychology, 4, 132-154. https://doi.org/10.1037/10892680.4.2.132

Frankl, V. E. (2013). İnsanın anlam arayışı. İstanbul: Okuyan Us.

Hazan, C., Shaver, P. R. (1987). Romantic love conceptualized as an attachment process. Journal of Personality and Social Psychology, 52, 511524. https://doi.org/10.1037/0022-3514.52.3.511

Impett,E.A., Gordon,A.M., Strachman, A. (2008). Attachment And daily sexual goals: A study of dating couples. Personal Relationships. 15, 375390. https://doi.org/10.1111/j.1475-6811.2008.00204.x

Jones, G. D. and Nelson, E. S. (1997). Expectations of marriage among college students from intact and non-intacthomes. Journal of Divorce $\mathcal{E}$ Remarriage, 26(12), 171-189. https://doi.org/10.1300/J087v26n01_09

Karasar, N (2016). Bilimsel Araştırma Yöntemi. Ankara: Nobel Akademik Yayıncilik.

Kocayörük, E , Altıntaş, E , Şïmşek, Ö , Bozanoğlu, İ, Çelik, B . (2018). Üniversite öğrencilerinin zaman perspektifli iyi-oluş düzeyleri: Kümeleme analizi incelemesi . Hacettepe Üniversitesi Eğitim Fakültesi Dergisi, 33(3) , 550-564 . Retrieved from https://dergipark.org.tr/tr/pub/hunefd/issue/38684/449412.

Koç, E . (2008). Bir umut metafiziği olarak gabriel marcel felsefesi . Süleyman Demirel Üniversitesi Fen-Edebiyat Fakültesi Sosyal Bilimler Dergisi, 2008(18),171-194.Retrievedfrom https://dergipark.org.tr/tr/pub/sufesosbil/issue/11420/136431 
Koçak, G. (2009). Cinsel benlik şemaları: Özdoyum ve cinsel etkinlik sıklı̆̆ı, cinsel doyum ve evlilik uyumu üzerindeki etkilerinin bir araştırması. Yüksek Lisans Tezi, ODTÜ Psikoloji Bölümü, Ankara.

Larson, J. H., Anderson, S. M., Holman, T. B., ve Niemann, B. K. (1998). A longitudinal study of the effects of premarital communication, relationship stability, and self-esteem on sexual satisfaction in the first year of marriage. Journal of Sex E Marital Therapy, 24(3), 193-206. doi: $\underline{10.1080 / 00926239808404933}$

Mccarthy B (1997). Strategies And Techniques For Revitalizing A Nonsexsual Marriage. Journal Of Sex ETherapy, 23(3),231-240. https://doi.org/10.1080/00926239708403928

Reker, G. T. (1992). Manual of the life attitude profile-revised. Peterborough, ON: Student Psychologists Press.

Selcuk, E., Gunaydin, G., Sumer, N., ve Uysal A. (2005). Yetişkin bağlanma boyutları için yeni bir ölçüm: Yakın İlişkilerde Yaşantılar EnvanteriII'nin Türk örnekleminde psikometrik açıdan değerlendirilmesi. Türk Psikoloji Yazıları [Turkish Psychological Articles], 8, 1-11.

Shaffer, J. A. (1978). Sexual desire. The Journal of Philosophy, 75(4), 175-189. https://doi.org/10.2307/2025657

Scheidler, J. A. (2008). Effects of perceived stress and perceived social support on marital satisfaction in doctoral students. Doctoral dissertation, Walden University, Washington, USA.

Sümer, N. (2002). Çocuklarda bağlanma ve duygusal gelişim. Çoluk Çocuk Dergisi, 3,12-14

Sümer, N., Ünal, S., Selçuk, E. (2009). Bağlanma ve Psikopatoloji: Bağlanma boyutlarının depresyon, panik bozukluk ve obsesif-kompulsif bozuklukla ilişkisi. Türk Psikoloji Dergisi, 24(63), 38-45.

Şahin, H. N. ve Yaka A. İ. (2010). Yakın İlişkilerde Yaşantılar Envanteri'nin (YIYYE-I), kendilik algısı, olumsuz otomatik düşünceler ve psikopatolojik belirtiler bağlamında incelenmesi. Türk Psikoloji Yazıları, 13(26), 64-76.

Şimşek, Ö. F. (2009). Happiness revisited: Ontological well-being as a theorybased construct of subjective well-being. Journal of Happiness Studies, 10(5), 505-522. https://doi.org/10.1007/s10902-008-9105-6 
Şimşek, Ö. F., Kocayörük, E. (2013). Affective reactions to one's whole life: Preliminary development and validation of the ontological wellbeing scale. Journal of Happiness Studies, 14(1), 309-343. https://doi.org/10.1007/s10902-012-9333-7

Tarhan, S , Bacanlı, H . (2016). İlkokuldan üniversiteye umut kavramının tanımlanması üzerine nitel bir çalışma . Eğitimde Nitel Araştırmalar Dergisi,4(2),86-112.Retrievedfrom https://dergipark.org.tr/tr/pub/enad/issue/32040/354580

Taycan, S. E., Kuruoğlu, A. Ç. (2014). Evlilik uyumu ile bağlanma stilleri ve mizaç ve karakter özellikleri arasındaki ilişkilerin incelenmesi. Türk Psikiyatri Dergisi, 25(1), 9-18

Trudel, G. (2002). Sexuality and Marital Life: Results of a Survey, Journal of Sex \& Marital Therapy, 229-249. https://doi.org/10.1080/009262302760328271

Tuğrul, C., Öztan, N. ve Kabakçı, E. (1993). Golombok-Rust Cinsel Doyum Ölçeği'nin standardizasyon çalışması. Türk Psikiyatri Dergisi, 4(2), 8388.

Waldvinger, R.(2015). What makes a good life? Lessons from the longest study on happines. www.ted.com. (Erişim tarihi: 24.12.2020)

Yıldırım, H.K. (2019). Bağlanma stillerinin ve ontolojik iyi oluşun cinsel doyum üzerine etkisi. Doktora Tezi. İstanbul Arel Üniversitesi Sosyal Bilimler Enstitüsü Klinik Psikoloji Doktora Programı, İstanbul.

\section{Kaynakça Bilgisi / Citation Information}

Yılmaztürk Yıldırım, H. K. (2021). Evli çiftlerde bağlanma stillerinin ve ontolojik iyi oluşun cinsel doyum üzerine etkisi. OPUS-Uluslararası Toplum Araştırmaları Dergisi, 18(39), 382-404. DOI: 10.26466/opus.851659. 